\title{
Antimicrobial use and antimicrobial resistance trends in Canada: 2014
}

\author{
Ebrahim $\mathrm{M}^{1}$, Gravel $\mathrm{D}^{1 *}$, Thabet $\mathrm{C}^{1}$, Abdesselam $\mathrm{K}^{1}$, Paramalingam $\mathrm{S}^{1}$, Hyson $\mathrm{C}^{1}$
}

\begin{abstract}
Background: There is a global concern that the emergence of antimicrobial resistance (AMR) threatens our ability to treat infectious diseases. The Canadian Antimicrobial Resistance Surveillance System (CARSS) was created in response to the Government of Canada's commitment to address AMR. CARSS integrates information from nine different national surveillance systems for tracking antimicrobial use (AMU) and AMR in both humans and animals to inform AMU/AMR research and policy.
\end{abstract}

Objective: To provide highlights of CARSS data on antimicrobial use in humans and animals, AMR trends in human infections in both hospital and community settings and AMR bacteria found in food production animals.

Methods: Information on AMU in humans and animals is purchased and additional information on AMU in animals is collected through the Canadian Integrated Program for Antimicrobial Resistance Surveillance (CIPARS). AMR data in humans focuses on first priority organisms. Data on priority organisms for hospital-based AMR is collected through Canadian Nosocomial Infection Surveillance Program (CNISP), Canadian Tuberculosis Laboratory Surveillance System (CTBLSS), Canadian Tuberculosis Reporting System (CTBRS) and CIPARS. Data on communitybased AMR is collected through CTBLSS, CTBRS, CIPARS, the Antimicrobial-resistant Neisseria gonorrhoeae Surveillance System (ARNGSS) and the National Surveillance of Invasive Streptococcal Disease (NSISD). AMR data on animals is collected through CIPARS.

Results: In terms of antibiotic usage in 2014 , approximately $82 \%$ of antimicrobials were directed to food production animals, $18 \%$ to humans and less than one percent to companion animals (e.g., pets) and crops. Over the past five years, $73 \%$ of antimicrobials distributed to food production animals belonged to the same classes as those used in human medicine. Antibiotic usage in humans has remained relatively stable. Trends in 2014 for AMR in hospitals include declining rates of hospital-acquired Clostridium difficile to 3.4 cases per 1,000 patient admissions, methicillin-resistant Staphylococcus aureus (MRSA) infections to 2.89 cases per 10,000 patient days and vancomycin-resistant Enterococci (VRE) to 0.45 cases per 10,000 patient days. Resistance to a number of antimicrobials used to treat Streptococcus pneumoniae has decreased since the introduction of pneumococcal vaccine in 2010 . In contrast, trends in 2014 for AMR in the community included increasing rates of community-acquired N. gonorrhoeae $-52.4 \%$ of isolates were resistant to at least one antibiotic. Trends for carbapenem-resistant Enterobacteriaceae (CRE) were stable at 0.22 cases per 10,000 patient days. Also, between 2004 and 2014, nine percent of tuberculosis (TB) culture positive cases were resistant to at least one first line anti-tuberculosis drug and this has remained relatively stable over that time. Trends in 2014 for AMR in food production animals showed decreasing resistance of Escherichia coli and Salmonella species to third-generation cephalosporins (ceftriaxone) in poultry associated with a decrease in cephalosporin use on chicken farms but resistance to ciprofloxacin in Campylobacter species in chicken and cattle has been increasing.

Conclusion: Overall, antibiotic use in humans has not declined despite concerns about overuse. Although resistance rates of C. difficile, VRE, MRSA and AMR S. pneumoniae have been gradually decreasing, and drug-resistant tuberculosis and CRE have remained stable, community-associated drug-resistant N. gonorrhoeae has been increasing. Although efforts to decrease antibiotic use in animals have been met with some success, AMR continues to occur in fairly high levels in food production animals.

Suggested citation: Ebrahim M, Gravel D, Thabet C, Abdesselam K, Paramalingam S, Hyson C. Antimicrobial use and antimicrobial resistance trends in Canada: 2014. Can Comm Dis Rep 2016;42(11):227-31.

https://doi.org/10.14745/ccdr.v42i11a02

\section{Affiliation}

${ }^{1}$ Centre for Communicable Diseases and Infection Control, Public Health Agency of Canada, Ottawa, ON

*Correspondence: denise. graveltropper@phac-aspc.gc.ca 


\section{Introduction}

The extent of antimicrobial use (AMU) and antimicrobial resistance (AMR) are global concerns due to increased resistance levels detected in some pathogenic microbes and the selective pressure resulting from antimicrobial use in both animals and humans (1). The damaging effects of AMR are already manifesting themselves across the world with antimicrobial resistant infections currently claiming at least 50,000 lives each year across Europe and the US alone, with many hundreds of thousands more dying in other areas of the world (2). In order to monitor AMU/AMR in Canada, the Canadian Antimicrobial Resistance Surveillance System (CARSS) was created. Through collaboration with internal and external stakeholders, CARSS integrates several sources of AMU/AMR surveillance information to provide a unified national picture of AMU and AMR in humans and animals in Canada. Data on both humans and animals is included because inappropriate antimicrobial use in food production animals is a public health concern as it contributes to the emergence of resistant bacteria in animals that can be transmitted to humans through the food supply (3). The first CARSS Report, issued in March 2015, provided information on AMU/AMR in Canada until 2013 (4).

The objective of this summary is to highlight the key findings of the CARSS second report summarizing surveillance data up to 2014. The full report is available online (5).

\section{Methods}

Information is collected in four key areas: AMU in humans, AMU in animals, AMR in humans in health care and community settings and AMR in food production animals.

\section{Antimicrobial usage in humans and animals} CARSS purchases human AMU data from IMS Health Canada Inc., a global company that collects information on hospital antibiotic purchases and prescriptions dispensed by retail pharmacies in the community as well as antimicrobials prescribed by physicians. CARSS obtains animal AMU data from the Canadian Animal Health Institute (CAHI) which collects data on over $90 \%$ of all sales of licensed animal pharmaceutical products in Canada. The Public Health Agency of Canada (PHAC) collects additional AMU information from sentinel farms through the Canadian Integrated Program for Antimicrobial Resistance Surveillance (CIPARS). CIPARS monitors trends in AMU and AMR in selected bacterial organisms from human, animal and food sources across Canada (6).

\section{AMR in humans}

\section{Health care settings}

CARSS collects data concerning AMR in priority organisms transmitted in health care settings through a number of different surveillance systems. The Canadian Nosocomial Infection Surveillance Program (CNISP) tracks C. difficile, carbapenemase producing organisms (CPO) and carbapenem-resistant Enterobacteriaceae (CRE), methicillin-resistant $S$. aureus (MRSA) and vancomycin-resistant Enterococci (VRE) (7). Human Salmonella isolates in hospitals are captured through CIPARS (8). Data on hospital tuberculosis (TB) cases are provided through the Canadian Tuberculosis Laboratory Surveillance System
(CTBLSS) and the Canadian Tuberculosis Reporting System (CTBRS) (9).

\section{Community settings}

AMR is monitored for the following priority organisms primarily transmitted in community settings: Streptococcus pneumoniae, Group A Streptococcus, Neisseria gonorrhoeae and Mycobacterium tuberculosis. Provincial public health laboratories submit isolates to the National Microbiology Laboratory (NML) for serotyping for Streptococcus and Neisseria gonorrhoeae. AMR data concerning Mycobacterium tuberculosis is forwarded to PHAC through the CTBLSS and CTBRS (9).

\section{AMR in food production animals}

CIPARS includes susceptibility testing for the following priority bacteria transmitted to humans through food production animals: generic Escherichia coli, Campylobacter and Salmonella species (8). E. coli samples are collected at three different spots along the food chain (farms, slaughter houses and retail stores) for chicken and swine and from slaughter houses or retail stores for cattle. Campylobacter samples are collected across the food chain for chicken and are collected only from slaughter houses for swine and cattle; Salmonella species samples are collected at farms and slaughter houses for chickens (5).

A summary of all the data collected by CARSS on AMR on priority organisms for both humans and animals is summarized in Table 1.

\section{Table 1: Sources of antimicrobial resistance data provided to CARSS in humans and animals}

\begin{tabular}{|c|c|c|c|}
\hline $\begin{array}{l}\text { Data } \\
\text { collected }\end{array}$ & $\begin{array}{l}\text { Surveillance } \\
\text { system }\end{array}$ & Pathogens & $\begin{array}{c}\text { Provides information } \\
\text { for: }\end{array}$ \\
\hline \multirow[t]{3}{*}{ Hospital AMR } & CNISP & $\begin{array}{l}\text { - Methicillin-resistant } \\
\text { Staphylococcus aureus } \\
\text { - Clostridium difficile } \\
\text { - Vancomycin-resistant } \\
\text { enterococci } \\
\text { - Carbapenem-resistant } \\
\text { Enterobacteriaceae } \\
\text { (CRE) and } \\
\text { Carbapenemase } \\
\text { producing organisms } \\
\text { (CPO): } \\
\text { - CP Acinetobacter } \\
\text { species (CPA) } \\
\text { - CP } \\
\text { Enterobacteriaceae } \\
\text { (CPE) }\end{array}$ & $\begin{array}{l}\text { - Health care- and } \\
\text { community-associated } \\
\text { infections in acute-care } \\
\text { hospitals }\end{array}$ \\
\hline & $\begin{array}{l}\text { CTBLSS \& } \\
\text { CTBRS }\end{array}$ & $\begin{array}{l}\text { - Mycobacterium } \\
\text { tuberculosis }\end{array}$ & - Drug resistance patterns \\
\hline & CIPARS & - Salmonella & - Hospital cases \\
\hline \multirow{4}{*}{$\begin{array}{l}\text { Community } \\
\text { AMR }\end{array}$} & $\begin{array}{l}\text { CTBLSS \& } \\
\text { CTBRS }\end{array}$ & $\begin{array}{l}\text { - Mycobacterium } \\
\text { tuberculosis }\end{array}$ & - Drug resistance patterns \\
\hline & ARNGSS & - Neisseria gonorrhoeae & $\begin{array}{l}\text { - Antimicrobial } \\
\text { susceptibility }\end{array}$ \\
\hline & CIPARS & - Salmonella & - Community cases \\
\hline & NSISD & $\begin{array}{l}\text { - Streptococcus } \\
\text { pneumoniae } \\
\text { - Streptococcus } \\
\text { pyogenes } \\
\text { - Streptococcus } \\
\text { agalactiae }\end{array}$ & $\begin{array}{l}\text { - Antimicrobial } \\
\text { susceptibilities }\end{array}$ \\
\hline $\begin{array}{l}\text { Production } \\
\text { animal AMR }\end{array}$ & CIPARS & $\begin{array}{l}\text { - Escherichia coli } \\
\text { - Campylobacter } \\
\text { - Salmonella species }\end{array}$ & $\begin{array}{l}\text { - Resistance in foodborne } \\
\text { bacteria in chicken, } \\
\text { swine and cattle }\end{array}$ \\
\hline \multicolumn{4}{|c|}{$\begin{array}{l}\text { Abbreviations: AMR, antimicrobial resistance; ARNGSS, Antimicrobial-resistant Neisseria } \\
\text { gonorrhoeae Surveillance System; CIPARS, Canadian Integrated Program for Antimicrobial } \\
\text { Resistance Surveillance; CNISP, Canadian Nosocomial Infection Surveillance Program; CTBLSS, } \\
\text { Canadian Tuberculosis Laboratory Surveillance System; CTBRS, Canadian Tuberculosis Reporting } \\
\text { System; NSISD, The National Surveillance of Invasive Streptococcal Disease }\end{array}$} \\
\hline
\end{tabular}




\section{SURVEILLANCE}

\section{Analysis}

Due to the nature of the method used to collect the data from the established surveillance systems, statistical analysis is descriptive. Numerous years of data facilitated the establishment of benchmarks and the analysis of trends over time.

\section{Results}

\section{Antimicrobial use}

Approximately 1.4 million kilograms $(\mathrm{kg})$ of medically important antimicrobials were distributed and/or sold in 2014. Approximately $82 \%$ were used in food production animals, $18 \%$ for humans and less than one percent for both companion animals and crops. In humans, the predominant classes of antimicrobials sold were $\beta$-lactams, cephalosporins and fluoroquinolones. In animals, the predominant classes were tetracyclines, $\beta$-lactams and "other" antimicrobials (Figure 1).

Figure 1: Kilograms of antimicrobials distributed and/or sold for use in animals and humans by antimicrobial class, 2014

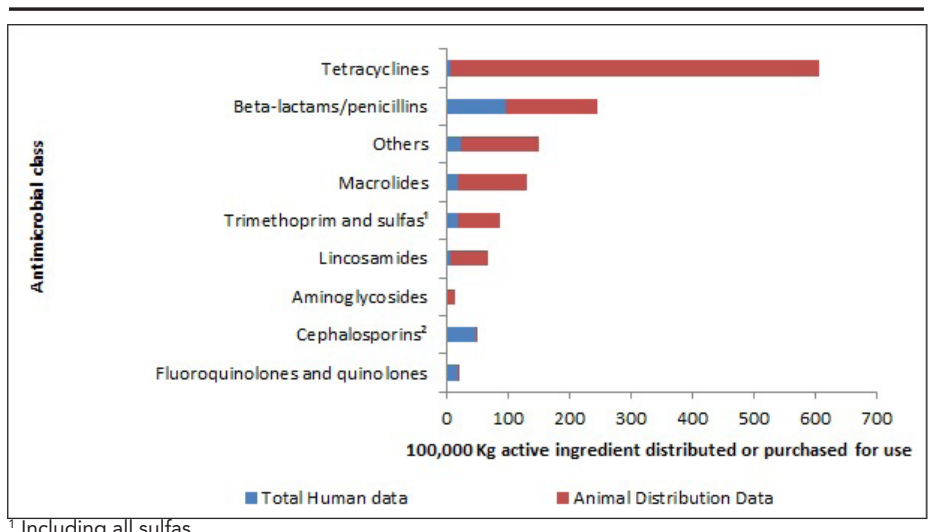

$21^{\text {st }}$ generation, $2^{\text {nd }}$ generation, others

Over the past five years (2010 to 2014) 73\% of antimicrobials distributed to food production animals belonged to the same classes as those used in human medicine, with 1.5 million $\mathrm{kg}$ of antimicrobial active ingredients distributed for use in animals in 2014. This is a 5.0\% increase from 2013.

\section{Usage in humans}

AMU in humans has remained relatively stable in Canada over the last 13 years. In 2014, compared to 2013, there was little change in the total number of antimicrobials dispensed by community pharmacies whereas hospital purchases decreased by $4.0 \%$. Antimicrobials dispensed by community pharmacies accounted for $93 \%$ of all antimicrobial use. Between 2010 and 2014 , prescribing rates for antimicrobials declined among children ( $0-14$ years) by $8.0 \%$, and among adults (15-59 years) by $3.0 \%$, but decreases were not observed among seniors $(60+$ years $)$.

In 2014, 38,340 kg of antimicrobials were purchased by hospitals across Canada at a cost of $\$ 104$ million. Ciprofloxacin was the antimicrobial most commonly purchased in 2014, followed by amoxicillin, azithromycin, ceftriaxone and doxycycline. Purchases of ceftriaxone and doxycycline have had the highest increase from 2002 to 2014

The majority of antimicrobials used in the Canadian outpatient population in 2014 were drugs for oral administration. Compared to 2013, parenteral (intravenous) antimicrobials dispensed at higher levels in 2014 included daptomycin, ticarcillin and clavulanic acid, fosfomycin, imipenem and cilastatin, ceftazidime, ceftriaxone and colistin. A steady increase has been noted over the last five years in dispensing of parenteral antimicrobials.

In 2014, antimicrobials were the recommended treatment in eight percent of all diagnoses. The majority of recommendations were for the treatment of respiratory infections including upper respiratory tract infections, bronchitis and acute sinusitis (Figure 2). This a concerning trend because antibiotics are not recommended as a first line of treatment in acute bronchitis or acute sinusitis $(10,11)$. Generally, the percentage of diagnoses for which an antimicrobial was recommended remained stable.

Figure 2: Number of specific diagnoses per person and the percentage of those diagnoses with recommendations for an antimicrobial in Canada, 2014

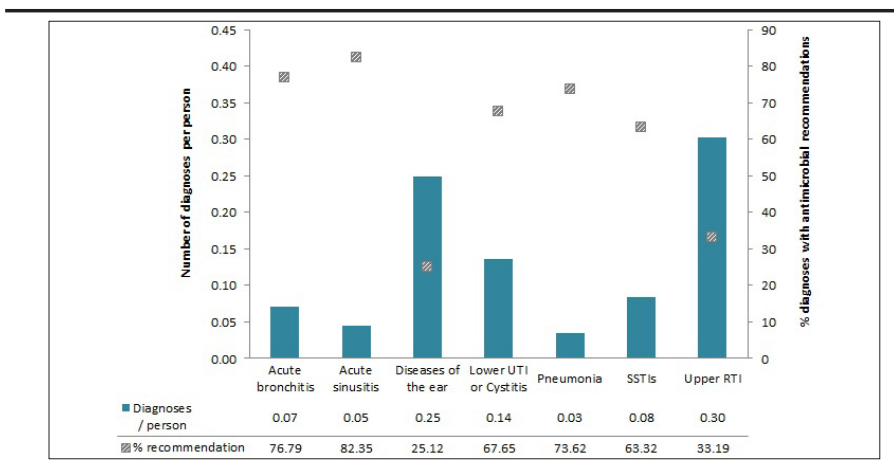

Usage in food production animals

Fluoroquinolones are classified as of "very high importance to human medicine" by Health Canada's Veterinary Drugs Directorate. Since 2010 there has been a $40 \%$ increase in the quantity of fluoroquinolones distributed for use in animals, likely due in part to the approval of a new indication for fluoroquinolone use. Between 2013 and 2014, the quantity increased by $14 \%$. Third-generation cephalosporins are also highly important to human medicine because they are a last line of defence. CAHI data show a $60 \%$ decline in the quantity of cephalosporins distributed for use in animals from 2011 to 2014.

As shown in Figure 3, after adjusting for animal population numbers and weight (green line), the overall quantity of antimicrobials distributed has remained relatively stable over time with a $3.0 \%$ increase since 2006 and a $1.0 \%$ increase since 2013. Over the past five years (2010-2014), this amount has increased by $16 \%$.

Figure 3: Medically-important antimicrobials distributed for use in animals over time; measured as kilograms active ingredient and milligrams active ingredient, adjusted for populations and weights, 2006 to 2014

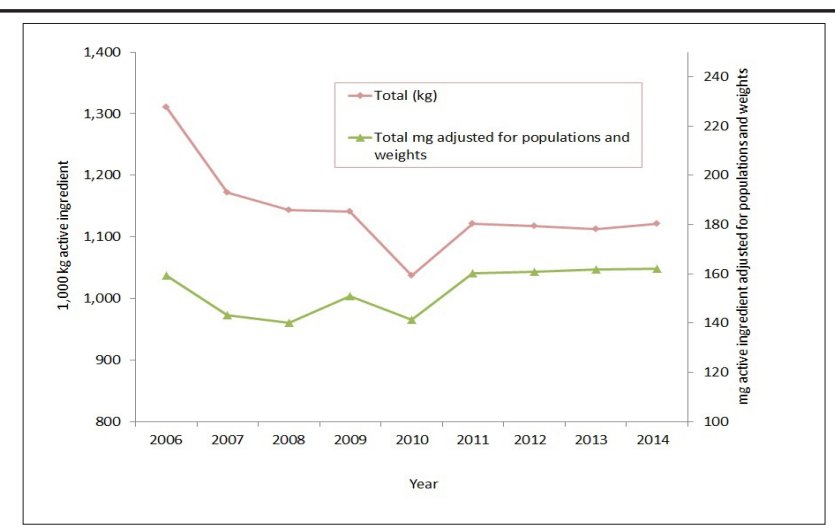




\section{AMR in humans}

\section{Health care settings}

In health care settings AMR trends are tracked for first priority organisms (those identified as of highest concern) (Table 2).

Table 2: Trends in antimicrobial resistance for organisms identified as priority organisms primarily transmitted in health care settings

\begin{tabular}{|l|l|}
\hline \multicolumn{1}{|c|}{ Priority organism ${ }^{1}$} & \multicolumn{1}{c|}{ AMR trends } \\
\hline $\begin{array}{l}\text { Healthcare acquired } \\
\text { (HAstridium difficile }\end{array}$ & $\begin{array}{l}\text { The overall HA-CDI infection rates peaked } \\
\text { in 2008 at 5.8 HA-CDI infections per 1,000 } \\
\text { patient admissions then declined slowly to } \\
\text { approximately 3.4 HA-CDI infections per 1,000 } \\
\text { admissions in 2014. }\end{array}$ \\
\hline $\begin{array}{l}\text { Carbapenem-resistant } \\
\text { (CRE) }\end{array}$ & $\begin{array}{l}\text { CRE rates remained relatively stable from 2010 } \\
\text { to 2014. In 2014, rates were of 0.22 per 10,000 } \\
\text { patient days compared to 0.19 per 10,000 } \\
\text { patient days in 2010. }\end{array}$ \\
\hline $\begin{array}{l}\text { Enterococcus species } \\
\text { VRE infection rates increased sharply from } 0.1 \\
\text { cases per 10,000 patient days in 2007 to 0.61 } \\
\text { cases per 10,000 patient days in 2012 before } \\
\text { decreasing to 0.45 cases per 10,000 patient days } \\
\text { in 2014. }\end{array}$ \\
\hline $\begin{array}{l}\text { Methicillin resistant } \\
\text { (MRSA) }\end{array}$ & $\begin{array}{l}\text { MRSA infections have decreased approximately } \\
25 \% \text { since 2008 with infection rates decreasing } \\
\text { from 2.92 per 1,000 patient admissions in 2008 } \\
\text { to 2.12 per 1,000 patient admissions in 2016. }\end{array}$ \\
\hline
\end{tabular}

As developed and accepted by the CIDSC AMR Surveillance Task Group, December 2014 (unpublished report)

\section{Community settings}

Trends in AMR for first priority organisms in community settings are outlined in the 2016 CARSS Report (Table 3).

Table 3: Trends in antimicrobial resistance for organisms identified as of priority organisms primarily transmitted in community settings

\begin{tabular}{|c|c|}
\hline $\begin{array}{c}\text { Priority } \\
\text { organism }^{1}\end{array}$ & Antimicrobial resistance trends \\
\hline $\begin{array}{l}\text { Neisseria } \\
\text { gonorrhoeae }\end{array}$ & $\begin{array}{l}\text { In } 2014 \text {, a total of } 1,995 \mathrm{~N} \text {. gonorrhoeae samples }(52.4 \%) \text { were } \\
\text { found to be resistant to one or more antibiotic, representing } \\
\text { an increase in AMR since } 2009 \text {, especially to azithromycin, } \\
\text { ciprofloxacin, erythromycin, penicillin and tetracycline. }\end{array}$ \\
\hline \multirow{2}{*}{$\begin{array}{l}\text { Streptococcus } \\
\text { pyogenes \& } \\
\text { S. pneumoniae }\end{array}$} & $\begin{array}{l}\text { Resistance to a number of antimicrobials used to treat } \\
\text { S. pneumoniae has decreased since } 2010 \text { following the } \\
\text { introduction of a pneumococcal vaccine. For example, } \\
\text { resistance to penicillin declined from } 12 \% \text { in } 2011 \text { to } 9 \% \text { in } \\
2014 \text {. }\end{array}$ \\
\hline & $\begin{array}{l}\text { In } 2014 \text {, all samples of streptococcus pyogenes were sensitive } \\
\text { to first line antimicrobials while resistance to second line drugs } \\
\text { were unchanged or declined since } 2010 \text {. }\end{array}$ \\
\hline $\begin{array}{l}\text { Mycobacterium } \\
\text { tuberculosis }\end{array}$ & $\begin{array}{l}\text { Between } 2004 \text { and } 2014,9 \% \text { of culture positive cases were } \\
\text { found to be resistant to at least one first line anti-tuberculosis } \\
\text { drugs. Isoniazid resistance was the most common pattern } \\
\text { of resistance reported. Also, for the same time period, } 8 \% \\
\text { of the culture positive cases were monoresistant, } 0.5 \% \text { were } \\
\text { polyresistant and } 1 \% \text { were multi-drug resistant tuberculosis } \\
\text { (MDR-TB). Also, the proportion of cases with MDR-TB remained } \\
\text { relatively stable ranging between } 1 \% \text { and } 2 \% \text {. }\end{array}$ \\
\hline \multirow{2}{*}{$\begin{array}{l}\text { Salmonella } \\
\text { species }\end{array}$} & $\begin{array}{l}82 \% \text { of typhoidal isolates were resistant to nalidixic acid. } \\
\text { Ciprofloxacin resistance increased from } 2003 \text { to } 2014 \text { from } 0 \% \text { to } \\
14 \% \text {, with } 16 \% \text { being multiclass-resistant. }\end{array}$ \\
\hline & $\begin{array}{l}\text { Over time, resistance in non-typhoidal isolates has decreased since } \\
2004 \text { with the exception of nalidixic acid which has almost doubled } \\
\text { between } 2013(5 \%) \text { and } 2014 \text { (9\%). }\end{array}$ \\
\hline
\end{tabular}

As developed and accepted by the CIDSC AMR Surveillance Task Group, December 2014 (unpublished report)

\section{AMR in food production animals}

PHAC monitors AMR in select bacterial organisms in a number of food production animals across Canada. The 2014 data regarding AMR in food production animals is presented in Table 4.

Table 4: Trends in antimicrobial resistance for organisms transmitted through food production animals

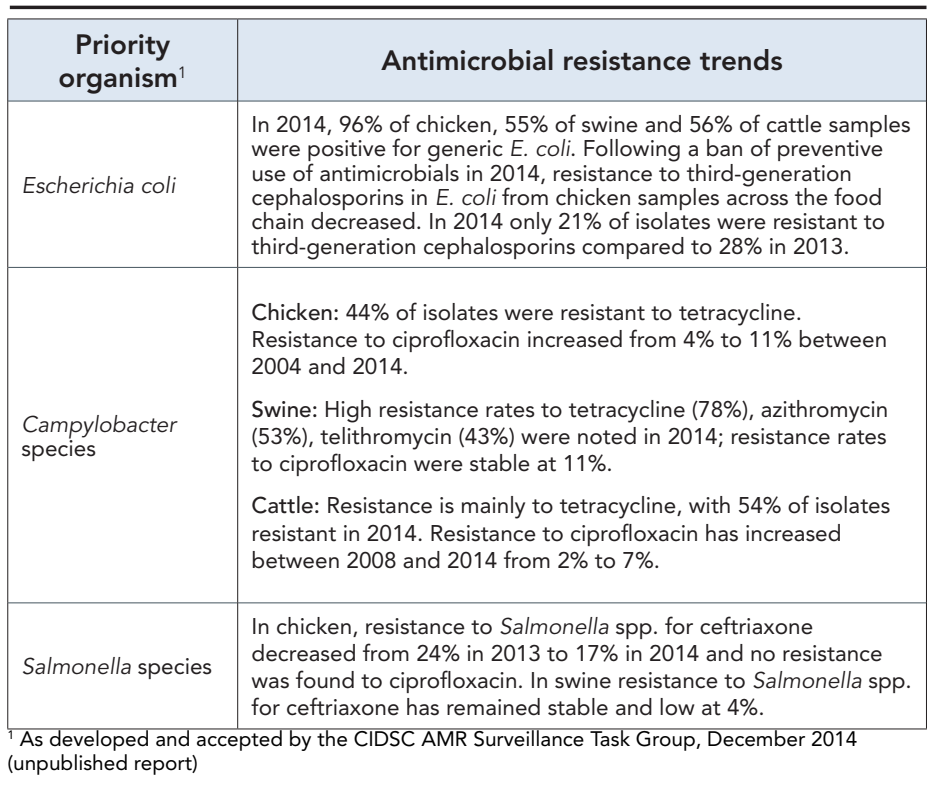

\section{Discussion}

The CARSS 2016 Report identified that in 2014, more than $80 \%$ of all antimicrobials distributed in Canada were directed to food production animals. Antimicrobial use in humans and animals has remained relatively stable over the past few years. Healthcare-associated $\mathrm{C}$. difficile infection, VRE and MRSA have decreased, whereas, CRE remained relatively stable. In the community, resistant $S$. pneumoniae has gradually decreased; drug-resistant $N$. gonorrhoea has increased, while drug-resistant TB has remained stable. In food production animals, resistance to third-generation cephalosporins in generic $E$. coli and Salmonella species has decreased in chicken, while resistance to ciprofloxacin in Campylobacter species and has increased in chicken and cattle.

With the implementation of CARSS, PHAC has improved the coordination of surveillance for AMU/AMR to assist stakeholders with the integrated data they need to inform further progress in reducing the threat of AMR and preserving the efficacy of today's antimicrobials.

Despite the advances in our surveillance capacity, gaps still exist. There is a need for more data on a number of priority pathogens (e.g., E. coli, Neisseria gonorrhoea and Shigella) and there is limited data on AMR in smaller, non-academic hospitals, including those in rural and northern health care settings and First Nations communities. Overall, there is limited data on AMR in the community, outpatient clinics, long-term care facilities and physicians' and dentists' offices. Data on AMU in animals is also limited. For example, data concerning the amounts of 
over-the-counter antimicrobials sold without veterinary prescription or the amounts imported as active pharmaceutical ingredients for compounding by veterinarians and/or used in food production animals is limited. Even with all the data we do have, we still do not completely understand the link between AMU and the emerging patterns of AMR in Canada.

PHAC is committed to addressing these surveillance gaps by working with provincial and territorial partners and other stakeholders to expand surveillance activities to collect quality data regarding health professional prescribing practices, infection rates and resistance patterns for key priority organisms, particularly in community settings. PHAC is also working with the World Health Organization to develop common indicators for AMR resistant pathogens.

\section{Acknowledgements}

The authors thank all members of The Canadian Nosocomial Infection Surveillance Program, The Canadian Integrated Program for Antimicrobial Resistance Surveillance, The Canadian Tuberculosis Laboratory Surveillance System, The Canadian Tuberculosis Reporting System, The Antimicrobial resistant Neisseria gonorrhoeae Surveillance System, The National Surveillance of Invasive Streptococcal Disease, The Canadian HIV Strain and Drug Resistance Surveillance System and The National Microbiology Laboratory. The authors would also like to acknowledge with thanks the Canadian Antimicrobial Resistance Surveillance System (CARSS) team for the creation of materials and Figures used in this summary.

\section{Conflict of interest}

None.

\section{Funding}

This work was supported by the Public Health Agency of Canada.

\section{References}

1. World Health Organization [Internet]. Antimicrobial resistance: Global report on surveillance 2014. Geneva: WHO; June 2014. Available from: http://apps.who.int/iris/ bitstream/10665/112642/1/9789241564748_eng.pdf?ua=1.

2. O'Neill J [Internet]. Antimicrobial resistance: Tackling a crisis for the health and wealth of nations. London, UK: Review on Antimicrobial Resistance; December 2014. Available from: https://amr-review.org/sites/default/files/AMR\%20
Review\%20Paper\%20-\%20Tackling\%20a\%20crisis\%20for\%20 the\%20health\%20and\%20wealth\%20of\%20nations_1.pdf.

3. Centers for Disease Control and Prevention [Internet]. National Antimicrobial Resistance Monitoring System for Enteric Bacteria (NARMS). Antibiotic use in food production animals. Atlanta, GA: CDC; 2014. [updated 2016 Mar 29; cited 2016 Oct 05]. Available from: https://www.cdc.gov/ narms/animals.html.

4. Public Health Agency of Canada [Internet]. Canadian Antimicrobial Resistance Surveillance System: Report 2015. Ottawa, ON: PHAC; March 2015. Available from: http:// healthycanadians.gc.ca/alt/pdf/publications/drugs-productsmedicaments-produits/antibiotic-resistance-antibiotique/ antimicrobial-surveillance-antimicrobioresistance-eng.pdf? ga=1.101498113.1672826305.1472829660.

5. Public Health Agency of Canada [Internet]. Canadian Antimicrobial Resistance Surveillance System - Report 2016. Ottawa, ON: PHAC; March 2015. Available from: http://healthycanadians.gc.ca/publications/drugs-productsmedicaments-produits/antibiotic-resistance-antibiotique/alt/ pub-eng.pdf.

6. Government of Canada [Internet]. Human antimicrobial use report - 2014. Guelph ON: Public Health Agency of Canada; November 2015. [updated 2015 Nov 17; cited 2016 Oct 05]. Available from: http://healthycanadians.gc.ca/publications/ drugs-products-medicaments-produits/human-antimicrobialuse-2014-utilisation-antimicrobiens-humains/index-eng.php.

7. Public Health Agency of Canada [Internet]. Antimicrobial resistant organisms (ARO) surveillance: Summary report for data from January 1, 2009 to December 13, 2014. Ottawa, ON: PHAC; August 2015. [updated 2016 Sept 29; cited 2016 Oct 05]. Available from: http://healthycanadians. gc.ca/publications/drugs-products-medicaments-produits/ antimicrobial-summary-sommaire-antimicrobien/index-eng. php.

8. Public Health Agency of Canada [Internet]. CIPARS 2013 Annual report: Chapter 1. Design and methods. Ottawa, ON: PHAC; 2014. Available from: http://www.phac-aspc. gc.ca/cipars-picra/2013/annu-report-rapport-eng.php.

9. Public Health Agency of Canada [Internet]. Tuberculosis in Canada 2014 report. Ottawa, ON: PHAC; June 2016. Available from: http://healthycanadians.gc.ca/publications/ diseases-conditions-maladies-affections/tuberculosis-2014tuberculose/index-eng.php\#a3.

10. Alberta Medical Association [Internet]. Guidelines for the management of acute bronchitis. 2008 update. Edmonton, AB: Alberta Medical Association; 2008. Available from: http://www.topalbertadoctors.org/download/378/acute_ bronchitis_guideline.pdf.

11. Rosenfield RM, Picirrilo JF, Chandrasekhar SS, et al. Clinical practice guideline update: Adults sinusitis executive summary. Otolaryngol Head Neck Surg. 2015 Apr;152(4):598-609. 